\title{
Uma Análise da Evasão em Cursos de Graduação Apoiado por Métricas e Visualização de Dados
}

\author{
Emanuel F. Coutinho' ${ }^{1}$, Jagni Dasa Horta Bezerra ${ }^{1}$ \\ Carla I. Moreira Bezerra², Leonardo O. Moreira' ${ }^{1}$ \\ ${ }^{1}$ Instituto Universidade Virtual (UFC VIRTUAL) \\ Universidade Federal do Ceará (UFC) - Fortaleza - CE - Brasil \\ ${ }^{2}$ Universidade Federal do Ceará (UFC) - Quixadá - CE - Brasil \\ \{emanuel,jagni\}@virtual.ufc.br, carlailane@ufc.br, \\ leoomoreira@virtual.ufc.br
}

\begin{abstract}
School dropout is the interruption of study at any level of education, occurring much at undergraduate level. However, it is difficult to obtain dropout data in undergraduate courses, as well its calculation method for causes analysis and identification. In this context, we can use data visualization for a better analysis and decision making on the dropout causes. The objective of this work is to analyze the undergraduate courses dropout through metrics, supported by data visualization. We conducted a case study in two semesters of an undergraduate course. The results indicated metrics and visualization techniques facilitate dropout analysis and the causes identification for decision making.
\end{abstract}

Resumo. Evasão escolar é a interrupção do estudo em qualquer nível de educação, ocorrendo muito a nível de cursos de graduação. No entanto, é difícil obter dados sobre a evasão no ensino superior, assim como seu cálculo para análise e identificação de suas causas. Neste contexto, pode-se utilizar visualização de dados para uma melhor análise e tomada de decisão sobre as causas da evasão. O objetivo deste trabalho é analisar a evasão em cursos de graduação por meio de métricas, apoiada por visualização de dados. Um estudo de caso foi realizado com dados de dois semestres de um curso de graduação. Os resultados indicaram que métricas e técnicas de visualização facilitam a análise da evasão e a identificação de suas causas para tomada de decisões.

\section{Introdução}

A evasão escolar é uma crescente dificuldade enfrentada em diversas áreas do conhecimento, sendo um problema que deve ser tratado cuidadosamente. A evasão ou abandono escolar é um dos problemas mais complexos e cruciais no campo da educação, impregnando os vários níveis e modalidades de ensino e gerando danos sociais, econômicos, políticos, acadêmicos e financeiros a todos os envolvidos no processo educacional [Martinho et al., 2013]. Sendo assim, o desenvolvimento de métodos eficientes para a previsão dos alunos em risco de abandono se torna essencial, permitindo a adoção de ações proativas para minimizar tal situação. 
VII Congresso Brasileiro de Informática na Educação (CBIE 2018)

Anais do XXIV Workshop de Informática na Escola (WIE 2018)

Para esclarecer o conceito de evasão, uma comissão especial para o estudo de evasão [MEC, 1997] definiu a evasão dos cursos de graduação como a saída definitiva do aluno de seu curso de origem, sem concluí-lo. Também foi proposta a seguinte distinção: (i) evasão de curso, onde o estudante desliga-se do curso superior em situações diversas como abandono (não se matricula), desistência (oficial), transferência ou recepção (mudança de curso) e exclusão institucional; (ii) evasão da instituição, onde o estudante desliga-se da instituição na qual está matriculado; e (iii) evasão do sistema, na qual o estudante abandona de forma definitiva ou temporária o ensino superior. Essa mesma comissão descreveu algumas formas para o cálculo da evasão.

Um dos problemas relacionados à evasão é como se obter os dados e como analisá-los para a identificação de causas e efeitos. Muitas vezes, instituições de ensino possuem os dados necessários para se investigar a evasão. Por exemplo, alunos ingressantes em cursos, alunos desistentes de cursos, quantidade de trancamentos de matrícula e quantidade de reprovações em turmas. Entretanto, tais dados são geralmente despadronizados, redundantes, desatualizados e muitas vezes inacessíveis ou ilegíveis.

Diversos trabalhos abordaram a evasão sob diferentes perspectivas e variadas proposições para sua identificação e minimização [Manhães et al., 2011] [Rigo et al., 2014] [Queiroga et al., 2015] [Reino et al., 2015] [Silva et al., 2015] [Barbosa et al., 2017]. Porém, poucos trabalhos sobre o uso de técnicas e estratégias de visualização de dados como ferramenta de auxílio no combate à evasão foram encontrados.

Por visualização de dados entende-se uma melhor compreensão dos dados e identificação de suas relações. Visualização de dados possui muitas áreas de aplicação e formas de representação [Herman et al., 2000]. Pode-se destacar como exemplos de representação: hierarquia de árvores, organograma e taxonomias que retratam as relações entre elementos. Em Biologia e Química, gráficos são aplicados a árvores evolutivas, mapas moleculares ou genéticos e funções das proteínas. Outras áreas de aplicação incluem sistemas orientados a objetos, estruturas de dados, sistemas de tempo real, diagramas de fluxo de dados, diagramas de relacionamento da entidade (banco de dados), diagramas de representação do conhecimento, lógica de programação, esquemas de circuitos, dentre muitos outros. Ressalta-se que a informação nem sempre está disposta em hierarquias, requerendo técnicas para tratar gráficos mais gerais e diferenciados.

Esta pesquisa tem como objetivo analisar a evasão em cursos de graduação por meio de métricas diretamente e indiretamente relacionadas, apoiada por visualização de dados, identificando possíveis causas para a evasão. Para o atendimento deste objetivo, dois semestres consecutivos de um curso de graduação foram estudados, visando obter a quantidade de alunos que evadiram durante este período e identificar as principais causas destas evasões. Para a obtenção deste número, dados do sistema de gestão acadêmica da universidade foram analisados e uma adaptação do índice de evasão utilizado pelo MEC foi aplicada. Quanto à obtenção das causas, pesquisas quantitativas e qualitativas foram realizadas por meio de questionários online em ambos os semestres. Os dados obtidos possibilitaram a criação de diversas visualizações que demonstraram resultados positivos ao indicar problemas que influenciaram na evasão dos alunos. 
VII Congresso Brasileiro de Informática na Educação (CBIE 2018)

Anais do XXIV Workshop de Informática na Escola (WIE 2018)

\section{Trabalhos Relacionados}

Diversos trabalhos na literatura discutem a respeito do tema evasão escolar. Muitas vezes se descreve a evasão de um curso. Entretanto o valor da evasão não é algo fácil de se calcular, sendo muitas vezes analisado de forma indireta por meio de outras métricas.

Manhães et al. (2011) trabalharam na identificação precocemente do subconjunto dos alunos do curso de Engenharia da Escola Politécnica da UFRJ que apresentam risco de evasão utilizando técnicas de mineração de dados, identificando que através das primeiras notas semestrais dos ingressantes é possível identificar com precisão de 80\% a situação final do aluno no curso. Rigo et al. (2014) utilizaram técnicas de mineração de dados escolares e Learning Analytics para analisar a evasão sob vários aspectos, debatendo diversos significados atribuídos à evasão, além do uso de métricas do MEC para o cálculo da evasão e técnicas de visualização de dados convencionais, como gráficos de barra e linha, para análise dos dados obtidos.

Queiroga et al. (2015) descreveram os resultados iniciais de um trabalho para a predição precoce da evasão de alunos de um curso de Educação à Distância (EAD), utilizando apenas contagem de interações ao longo do tempo, uma vez que esta é uma métrica facilmente generalizável para outras plataformas e abordagens de ensino. Reino et al. (2015) realizaram pesquisas quantitativas e qualitativas tanto com alunos matriculados quanto com alunos evadidos, buscando obter as principais causas da evasão do curso de bacharelado em Sistemas de Informação na modalidade de EAD. Silva et al. (2015) investigaram como os dados armazenados em um Ambiente Virtual de Aprendizagem podem ser potencialmente úteis para apoiar o acompanhamento de alunos em cursos de EAD e implementaram uma ferramenta de visualização que organizava os resultados obtidos através de métodos de Mineração de Dados.

Barbosa et al. (2017) apresentaram uma estratégia de previsão de abandono de estudantes com base na classificação com o paradigma de opção de rejeição, que classifica alunos em classes propensas a abandonar ou a não abandonar. O método proposto pode ser ajustado para que o número de estudantes propensos à evasão possam ser atendidos pela força de trabalho disponível na instituição. Essa estratégia foi avaliada em um conjunto de dados de 892 estudantes de graduação de 2005 a 2016.

A Tabela 1 apresenta os seguintes critérios de comparação entre os artigos: utilização de visualização de dados, utilização ou construção de ferramentas, realização de experimentos, discussão de conceitos de evasão e utilização de métricas de evasão. Os artigos citados têm em comum a abordagem da evasão e evidenciam a importância de estudos sobre esta. Além disto, pode-se notar em vários deles o uso de mineração de dados como base para a predição de evasão.

Tabela 1. Comparação entre trabalhos relacionados

\begin{tabular}{|c|c|c|c|c|c|}
\hline Autor & Visualização & Ferramentas & Experimentos & Discussão & Métricas \\
\hline [Manhães et al., 2011] & Não & Sim & Sim & Sim & Não \\
\hline [Rigo et al., 2014] & Não & Não & Não & Sim & Sim \\
\hline [Queiroga et al., 2015] & Não & Sim & Sim & Sim & Não \\
\hline [Reino et al., 2015] & Sim & Não & Sim & Sim & Não \\
\hline [Silva et al., 2015] & Sim & Sim & Sim & Não & Não \\
\hline [Barbosa et al. 2017] & Sim & Não & Sim & Sim & Não \\
\hline
\end{tabular}


VII Congresso Brasileiro de Informática na Educação (CBIE 2018)

Anais do XXIV Workshop de Informática na Escola (WIE 2018)

A pesquisa proposta nesse trabalho se baseia nos artigos apresentados para definir parâmetros adequados para a identificação da evasão, sua importância e definições teóricas. Sua metodologia se assemelha a [Rigo et al. 2014] [Reino et al., 2015] e [Silva et al., 2015], com pesquisas realizadas com alunos visando o desenvolvimento de uma ferramenta de visualização dos dados obtidos e análise.

\section{Adaptação da Métrica para o Î́ndice de Evasão}

Para o cálculo da evasão, utilizou-se o índice para cálculo da evasão empregado pelo MEC [MEC, 1997] (Figura 1, Fórmula 1), capaz de medir a evasão verificada em um curso entre semestres subsequentes. Algumas adaptações foram necessárias para ajustar a métrica devido à natureza dos dados disponíveis sobre os alunos do curso e suas situações acadêmicas. As fórmulas ajustadas estão descritas na Figura 1.

\begin{tabular}{|c|c|c|}
\hline (1) & $I_{M E C}=\left[1-\left(\frac{M_{N}-I_{N}-R_{N}}{M_{N-1}-F_{N-1}}\right)\right] \times 100$ & 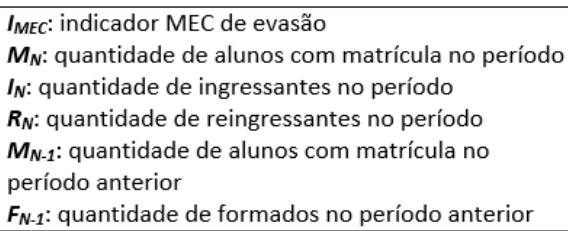 \\
\hline (2) & $I_{A}=\left[1-\left(\frac{M_{N}-I_{N}-R_{N}+T_{M}}{M_{N-1}-F_{N-1}}\right)\right] \times 100$ & $\begin{array}{l}I_{A}: \text { índice de evasão ajustado } \\
T_{M} \text { : situações de matrícula que discernem o } \\
\text { cancelamento e situações temporárias iniciadas no } \\
\text { semestre em questão (como programas de } \\
\text { intercâmbio). }\end{array}$ \\
\hline (3) & $R_{N}=M_{N}-I_{N}-R_{M}$ & $\begin{array}{l}R_{M}: \text { alunos que possuem matrícula no período em } \\
\text { questão e no período anterior }\end{array}$ \\
\hline (4) & $I_{A F}=\left[1-\left(\frac{R_{M}+T_{M}}{M_{N-1}-F_{N-1}}\right)\right.$ & $I_{A F}$ índice de evasão ajustado final \\
\hline
\end{tabular}

Figura 1. Fórmulas para o cálculo da evasão

A maioria dos dados foram extraídos do sistema de gestão acadêmica da universidade, como a quantidade de alunos matriculados em determinado período ( $\mathbf{M}_{\mathbf{N}} \mathrm{e}$ $\mathbf{M}_{\mathbf{N}-1)}$ e o número de ingressantes e transferidos ( $\left.\mathbf{I}_{\mathbf{N}}\right)$. Visto que tal índice não provê situações de matrícula que discernem o cancelamento e situações temporárias iniciadas no semestre em questão (como programas de intercâmbio), foi adicionada, então, uma nova variável ( $\left.\mathbf{T}_{\mathbf{M}}\right)$ que contempla este aspecto na Fórmula 2 da Figura 1.

Alunos são considerados reingressantes quando em algum momento evadiram o curso, porém reingressaram em determinado período $\left(\mathbf{R}_{\mathbf{N}}\right)$. Por não haver um meio direto de se obter tal dado, foi utilizada Fórmula 3 com os recursos disponíveis, considerando alunos rematriculados como aqueles que possuem matrícula no período em questão e no período anterior $\left(\mathbf{R}_{\mathbf{M}}\right)$. Ao se aplicar esta fórmula ao indicador de evasão ajustado, é obtido o índice de evasão ajustado final, representado pela Fórmula 4.

\section{Procedimentos Metodológicos, Resultados e Análises}

\subsection{Metodologia}

A pesquisa possui um caráter quantitativo e qualitativo. Para a análise da evasão, as seguintes etapas foram definidas: (i) Coleta de dados da ferramenta de controle acadêmico da universidade e dados da coordenação; (ii) Cálculo do índice da evasão, por meio das métricas ajustadas; (iii) Obtenção de dados de causas da evasão por meio 
VII Congresso Brasileiro de Informática na Educação (CBIE 2018)

Anais do XXIV Workshop de Informática na Escola (WIE 2018)

de pesquisas em formulários online; (iv) Criação de visualizações sobre os dados de evasão; e (v) Análise dos dados.

O experimento foi aplicado a dois semestres letivos (2015.1 e 2015.2) do curso de graduação Sistemas e Mídias Digitais (SMD) da Universidade Federal do Ceará, que tem como objetivo formar profissionais com conhecimentos especializados em duas principais áreas: Sistemas Multimídia e Mídias Digitais. Desta forma, o curso contribui para o desenvolvimento de novos perfis profissionais, de caráter interdisciplinar, que possam sustentar o desenvolvimento, viabilizando atividades produtivas nas áreas de geração de mídias digitais e desenvolvimento de sistemas multimídia, tais como: sistemas web, dispositivos móveis, jogos digitais e animações gráficas.

\subsection{Cálculo do Índice de Evasão}

Para o cálculo do índice de evasão, diversas fontes de dados foram utilizadas. Para a obtenção do número de alunos evadidos, foram utilizados os dados do sistema de gestão acadêmica da universidade, (Sistema Integrado de Gestão de Atividades Acadêmicas SIGAA). Também utilizou-se listas de controle de alunos em intercâmbio e alunos já formados, disponibilizadas pela coordenação do curso. A Tabela 2 exibe os valores das variáveis aplicadas no cálculo do índice de evasão, que ao aplicarmos à fórmula definem o indicador de evasão entre semestres.

Tabela 2. Cálculo do índice de evasão e suas variáveis

\begin{tabular}{|l|c|c|}
\hline Variáveis & $\mathbf{2 0 1 5 . 1}$ & $\mathbf{2 0 1 5 . 2}$ \\
\hline Formados no período anterior $\left(\mathbf{F}_{\mathbf{N}-\mathbf{1}}\right)$ & 7 & 10 \\
\hline Ingressantes $\left(\mathbf{I}_{\mathbf{N}}\right)$ & 63 & 63 \\
\hline Matriculados $\left(\mathbf{M}_{\mathbf{N}}\right)$ & 324 & 342 \\
\hline Matriculados no período anterior $\left(\mathbf{M}_{\mathbf{N}-\mathbf{1}}\right)$ & 283 & 324 \\
\hline Rematriculados $\left(\mathbf{R}_{\mathbf{M}}\right)$ & 249 & 268 \\
\hline Reingressantes $\left(\mathbf{R}_{\mathbf{N}}\right)$ & 12 & 11 \\
\hline Temporariamente afastados $\left(\mathbf{T}_{\mathbf{M}}\right)$ & 0 & 8 \\
\hline Índice de evasão (\%) & 9.78 & 12.10 \\
\hline
\end{tabular}

\subsection{Pesquisas Quantitativas e Qualitativas para Obtenção de Causas da Evasão}

Para a obtenção das possíveis causas da evasão, dois questionários online quantitativos e qualitativos foram aplicados com o objetivo de obter um panorama sobre vários aspectos do curso sob o ponto de vista dos alunos.

Os questionários possuíam questões em três dimensões: informações pessoais (sexo, idade, semestre de entrada no curso), informações sobre o curso e áreas de interesse (expectativas, projeto pedagógico, grade curricular, metodologia, professores, estrutura, áreas de interesse e mercado de trabalho) e identificação de problemas (destaques, áreas mais problemáticas, motivos para abandono). Além disso, uma comparação quantitativa por meio de gráficos entre os dois semestres foi realizada com todos os dados coletados. Ao final da pesquisa, foi gerado um relatório com todos esses dados e a consolidação de alguns aspectos do curso, para possibilitar a elaboração de um plano de melhorias para diversas áreas de atuação.

Estes questionários foram divulgados para preenchimento em canais de comunicação dos alunos como a lista de emails e redes sociais. Na pesquisa realizada no período 2015.1 houveram 97 respostas, enquanto na pesquisa realizada no período 
VII Congresso Brasileiro de Informática na Educação (CBIE 2018)

Anais do XXIV Workshop de Informática na Escola (WIE 2018)

2015.2 houveram 163 respostas. As questões utilizadas e os dados obtidos são de livre acesso e foram divulgados aos alunos, professores e coordenação. Por meio desses resultados, aspectos relacionados ao ensino e aprendizagem já puderam ser analisados.

\subsection{Desenvolvimento de Visualizações de Dados}

A partir dos dados obtidos pela pesquisa, alguns meios de representação foram estudados, com visualizações desenvolvidas por meio da biblioteca gráfica em javascript D3.js. Representações como a treemap, radar chart e gráficos de barras simples foram explorados e procurou-se prover uma legibilidade maior das informações obtidas através da pesquisa e do índice de evasão identificado no curso.

As Figuras 1 e 2 exibem treemaps para os dados coletados nas duas pesquisas realizadas. Um treemap é uma estrutura de visualização hierárquica, que possui uma distribuição dos dados dentro de um espaço limitado, e suas subdivisões, onde o tamanho de suas dimensões é proporcional ao valor numérico associado. Nem todos os dados da pesquisa foram desenhados no treemap, estando representados apenas seis dados coletados: Motivos para evasão, Curso deixa a desejar, Insegurança com mercado de trabalho, Grade curricular supre necessidades, Metodologia de ensino e Expectativas atendidas. Cada um desses dados possui suas categorias, conforme Tabela 3.

Tabela 3. Cálculo do índice de evasão e suas variáveis

\begin{tabular}{|l|l|}
\hline Descrição do Dado Coletado & Categorias \\
\hline Motivos para evasão & $\begin{array}{l}\text { Oportunidades, Reconhecimento profissional, Qualidade das aulas, } \\
\text { Organização Pedagógica, Problemas de Horário, Problemas Pessoais, } \\
\text { Identificação com o curso, Entrada em novo curso, Descontentamento } \\
\text { com Estrutura, Outros }\end{array}$ \\
\hline Curso deixa a desejar & $\begin{array}{l}\text { Corpo docente, Falta de reconhecimento ou valorização do mercado, } \\
\text { Desorganização em geral, Projeto Pedagógico, Estrutura do curso, Outro }\end{array}$ \\
\hline Insegurança com mercado de trabalho & Não, Parcialmente, Sim \\
\hline Grade curricular supre necessidades & Completamente, Razoavelmente, Parcialmente, Não \\
\hline Metodologia de ensino & $\begin{array}{l}\text { Muito Satisfatória, Satisfatória, Pouco Satisfatória, } \\
\text { Não Sei, Insatisfatória }\end{array}$ \\
\hline Expectativas atendidas & Sim, Não \\
\hline
\end{tabular}

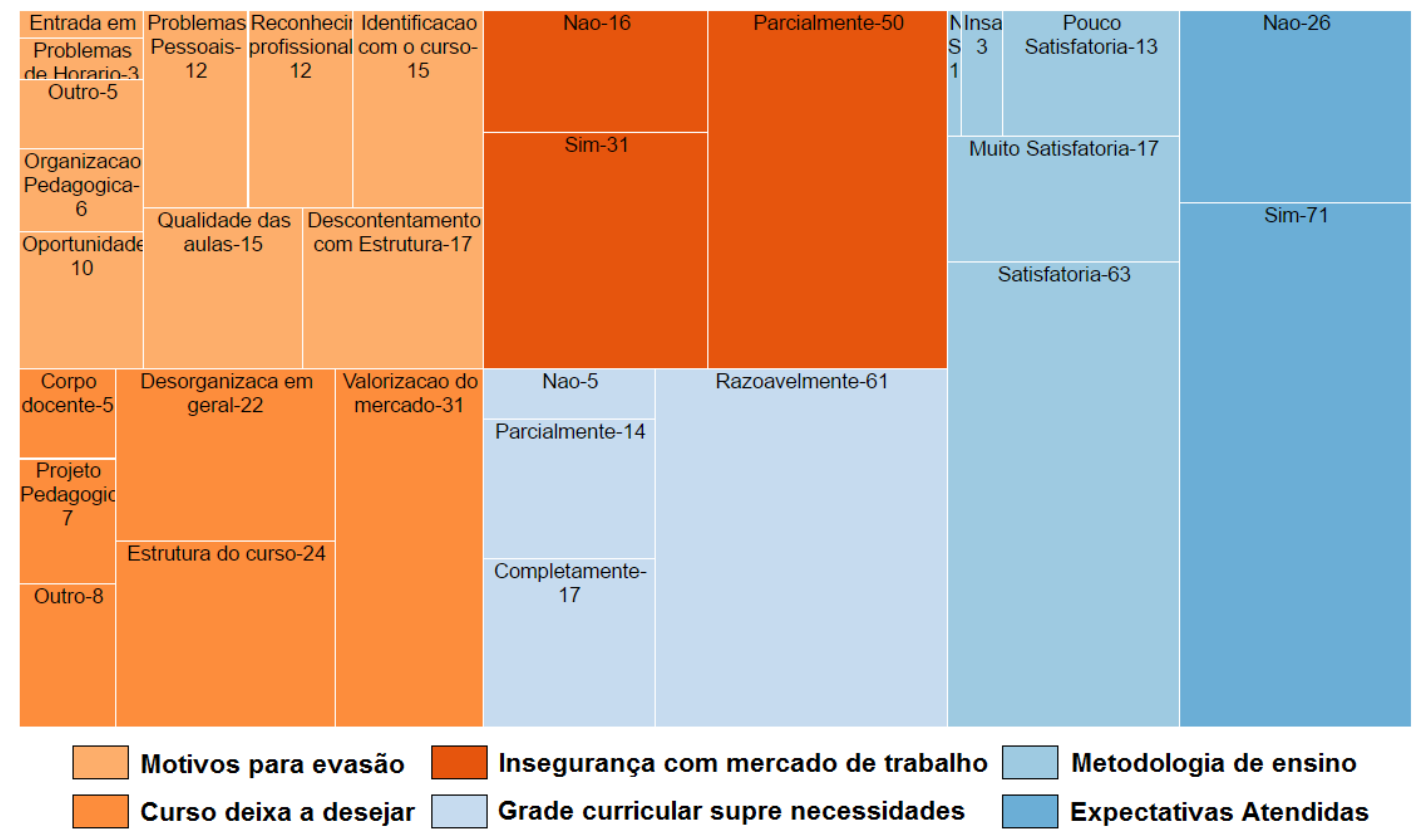


VII Congresso Brasileiro de Informática na Educação (CBIE 2018)

Anais do XXIV Workshop de Informática na Escola (WIE 2018)

Figura 1. Treemap para a pesquisa do semestre 2015.1

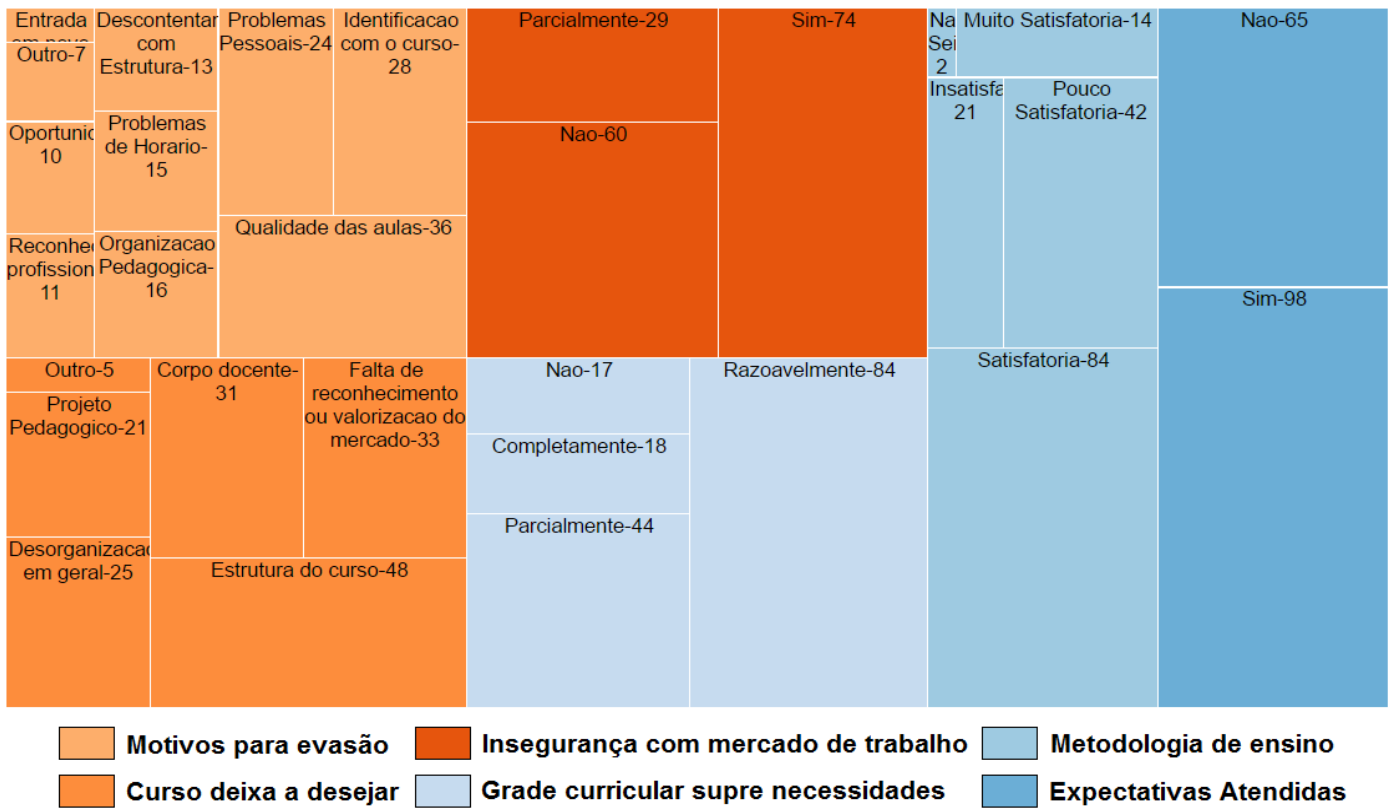

Figura 2. Treemap para a pesquisa do semestre 2015.2

Um radar chart (gráfico de radar) exibe dados multivariados na forma de um gráfico bidimensional de três ou mais variáveis quantitativas representada em eixos a partir do mesmo ponto. O radar chart foi utilizado para representar a pergunta "Qual o maior motivo para evadir o curso?”, comparando os resultados obtidos nas duas pesquisas, aspecto também representado no treemap. A Figura 3(a) exibe o radar chart para a questão. Outra visualização utilizada foi o sunburst. O sunburst é semelhante ao treemap, diferenciando-se por utilizar um esquema radial. O nó raiz da árvore está no centro, com as folhas na circunferência. A área (ou ângulo, dependendo da aplicação) de cada arco corresponde ao seu valor. A Figura 3(b) exibe um sunburst com suas dimensões representando as variáveis utilizadas no cálculo do índice de evasão.

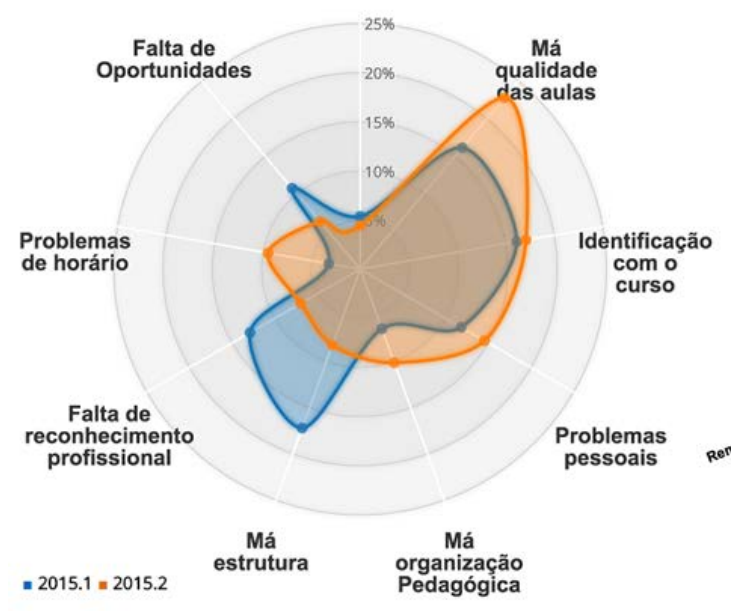

(a)

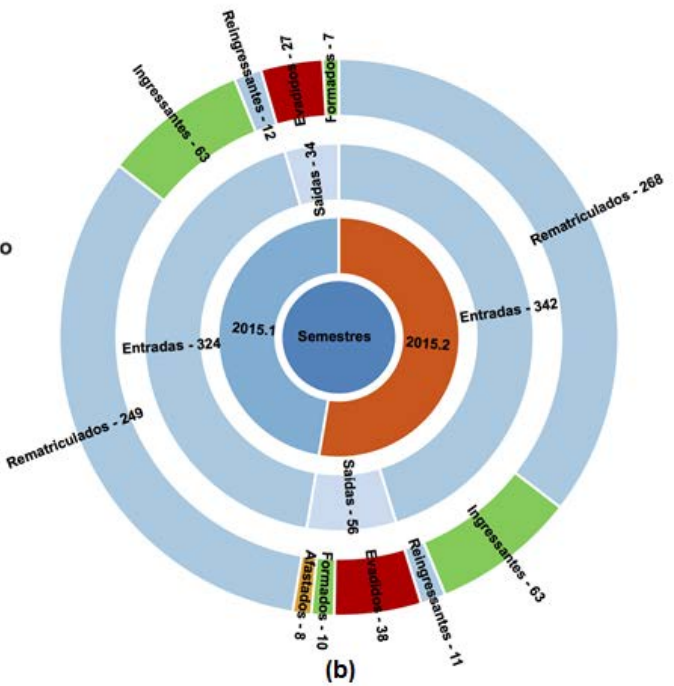

(b)

Figura 3. (a) Radar chart com motivos de evasão e (b) sunburst com as variáveis utilizadas no índice de evasão. Ambos para os dois semestres 
VII Congresso Brasileiro de Informática na Educação (CBIE 2018)

Anais do XXIV Workshop de Informática na Escola (WIE 2018)

\subsection{Análise dos Resultados}

O cálculo do índice de evasão resultou em 9.78\% e 12.10\%, respectivamente para os semestres 2015.1 e 2015.2. Mesmo sendo uma variação pequena, identificamos por meio de métricas indiretamente relacionadas a evasão que em geral os problemas aumentaram, sendo possíveis candidatos a provocar esse acréscimo na evasão.

Analisando os dois semestres pelo treemap, podemos identificar alguns fatores que explicam esse acréscimo no índice de evasão. Um dos itens analisados foi que sob o ponto de vista dos alunos o curso deixa a desejar. Desorganização do curso, falta de estrutura e insegurança em relação ao mercado foram fatores apontados em 2015.1. Em 2015.2, problemas em relação ao corpo docente superou a desorganização do curso. Em relação à insegurança com o mercado de trabalho, houve mais que o dobro de respostas de alunos sentindo-se inseguros a esse aspecto. O mesmo comportamento também ocorreu em relação à estrutura básica de funcionamento do curso.

No item metodologia de ensino, a satisfação ainda é alta, mas houve um decréscimo na proporcionalidade. Os motivos para evasão indicados pelos alunos foram semelhantes para os dois semestres. Para o primeiro semestre, os mais citados, praticamente com a mesma quantidade, foram a má qualidade das aulas, falta de estrutura e de identificação com o curso. Já no segundo semestre o mais citado foi a má qualidade das aulas e falta de identificação com o curso, que praticamente duplicou, adicionado do componente problemas pessoais.

Esse aspecto pode ser visualizado também pelo sunburst, e nele podemos visualizar de maneira mais fácil o que melhorou/piorou de um semestre para outro. Em relação à grade curricular, esta foi sinalizada como suprindo as necessidades do curso, relativamente proporcional, mas o a indicação de completamente suprindo diminuiu e o suprimento parcial cresceu.

Por fim, as expectativas atendidas do curso tiveram um decréscimo considerável na proporção, e no item relacionado ao que o curso deixa a desejar, se manteve problemas de estrutura e de mercado.

Analisando a Figura 3(b) e comparando com os valores da evasão, é possível verificar que para o semestre 2015.2, apesar de existirem mais alunos, há um acréscimo na evasão. Analisando especificamente o setor "saída" dos dois semestres, este é o local onde existem os alunos que se evadiram, com um número um pouco maior para 2015.2. (38 contra 27). Os motivos pelos quais esses alunos estão nessa situação merece ser investigado, pois alunos que não se matriculam no semestre estão nesta situação, e estes ainda podem retornar no semestre seguinte. Alunos afastados não são considerados evadidos, pois oficialmente eles estão no curso, e os formados realmente saíram do curso, mas não por desistência, e sim por conclusão. Um fato interessante é a quantidade de reingressantes, que diminuiu, mas mesmo assim o índice de evasão aumentou, o que indica que realmente está havendo uma evasão no curso.

As comprovações obtidas por meio das visualizações corroboram com o índice de evasão calculado, possibilitando uma análise em conjunto tanto gráfica quanto numérica, permitindo a elaboração e acompanhamento de planos de ação para minimizar a taxa de evasão. Como um plano de ação, as seguintes ações foram planejadas: realizar treinamento de didática no ensino para os professores; promover 
VII Congresso Brasileiro de Informática na Educação (CBIE 2018)

Anais do XXIV Workshop de Informática na Escola (WIE 2018)

interação com o mercado por meio de palestras, visitas e estágios; reorganizar a oferta/demanda de disciplinas e horários de turmas; acompanhar de forma mais próxima os professores com avaliação docente baixa. Algumas dessas ações estão em andamento, mas ainda não foram avaliadas quanto à efetividade, sendo este um trabalho futuro.

\subsection{Perspectivas de Expansão dos Resultados e da Pesquisa}

Alguns professores verificaram a utilidade das visualizações geradas. Em geral, os comentários foram que quando existem muitos dados, as imagens ficam confusas. E para o treemap há também certa dificuldade em perceber a diferença da relação entre o tamanho das imagens de certo atributo com outro, pois às vezes o retângulo correspondente está em uma posição diferente entre imagens distintas. O ideal é ter a menor quantidade possível de atributos para facilitar a visualização, interpretação e análise. Os números com as quantidades ajudaram muito no entendimento. Além disso, para o radar chart houve uma aceitação maior para a percepção de proporções.

Para grupos mais colegiados, como coordenação e unidades curriculares, os dados tiveram pouco impacto para suportar análises. De maneira geral, as visualizações não foram utilizadas devido a não existência de uma ferramenta mais intuitiva. Porém, a pesquisa foi citada algumas vezes como uma iniciativa do estudo de evasão no curso de graduação, podendo gerar mais conhecimento sobre o tema. Mesmo assim, apesar dos resultados iniciais não terem sido bem aproveitados, a pesquisa proporcionou 0 desenvolvimento de uma ferramenta de visualização de dados, sugestão de alguns professores, com vários gráficos diferentes, sob o formato de uma aplicação web. Esta ferramenta teve a base de dados de quatro semestres letivos (2015.1, 2015.2, $2016.1 \mathrm{e}$ 2016.2), disponíveis em relatórios consolidados. Como um trabalho futuro pretende-se ampliar essa ferramenta, com o cálculo automático da evasão por semestre. Também percebeu-se a necessidade de uma metodologia para a análise das imagens e métricas de maneira mais sistematizada, para facilitar a utilização e comparação dos resultados.

\section{Conclusões e Trabalhos Futuros}

A evasão é uma situação que deve ser tratada em todos os níveis escolares. Esse trabalho propôs uma métrica para o cálculo da evasão e algumas formas de visualizar dados relacionados para sua análise e identificação de causas e potenciais problemas. A utilização de uma métrica para o cálculo da evasão possibilitou comparar numericamente a evasão entre semestres, e com o suporte de visualização de dados foi possível identificar problemas mais facilmente e rapidamente.

A visualização de dados possibilita que ferramentas digitais sejam incorporadas aos processos de produção do conhecimento. Por meio de imagens, muitos dados que se dispostos de maneira textual ou tabular não seriam percebidos. Entretanto ressalta-se a importância de um cuidadoso projeto das imagens, pois elas podem distorcer dados ou serem inadequadas para a natureza dos dados em questão. No contexto da evasão de estudantes, a visualização de dados possibilitou comparar alguns aspectos que quando dispostos de maneira tabular ficava difícil de identificar potenciais problemas. E comparar com aspectos diversos também facilita a identificação das causas da evasão.

Com o desenvolvimento de uma ferramenta web que suporte o cálculo da evasão e gere dinamicamente gráficos, reforçaríamos também o uso das Tecnologias Digitais de 
VII Congresso Brasileiro de Informática na Educação (CBIE 2018)

Anais do XXIV Workshop de Informática na Escola (WIE 2018)

Informação e Comunicação (TDIC), se considerarmos sua aplicação de maneira mais ampla e acessível devido ao uso da internet, podendo ser uma ferramenta mediadora para a identificação de problemas. A ferramenta proposta a partir da ideia deste trabalho contempla essa disponibilização para a sociedade por meio da internet.

Como trabalhos futuros, pretende-se calcular para cada semestre do curso a evasão para obter o histórico do curso, e a cada semestre posterior reaplicar a pesquisa, avaliando as causas da evasão, e verificando se o plano de ações está sendo efetivo ou não. Além disso, pretende-se formalizar uma metodologia para o estudo da evasão apoiado por visualização de dados e métricas de evasão, e suportado por uma ferramenta interativa, ainda a ser projetada e desenvolvida.

\section{Referências}

Barbosa, A., Santos, E., Pordeus, J. P. (2017). A machine learning approach to identify and prioritize college students at risk of dropping out. In VI Congresso Brasileiro de Informática na Educação (CBIE 2017) - Anais do XXVIII Simpósio Brasileiro de Informática na Educação (SBIE 2017), pág. 1497-1506. SBC.

Herman, I., Melancon, G., Marshall, M. S. (2000) "Graph visualization and navigation in information visualization: A survey”, in IEEE Transactions on Visualization and Computer Graphics, vol. 6, no. 1, pp. 24-43, Jan-Mar 2000.

Manhães, L. M. B., Costa, R. J. M., Da Cruz, S. M. S., Zavaleta, J., Zimbrão, G. (2011) "Previsão de Estudantes com Risco de Evasão Utilizando Técnicas de Mineração de Dados”, Anais do XXII SBIE - XVII WIE, pág. 150.

Martinho, V. R. D. C., Nunes, C., Minussi, C. R. (2013) An Intelligent System for Prediction of School Dropout Risk Group in Higher Education Classroom Based on Artificial Neural Networks, 2013 IEEE 25th International Conference on Tools with Artificial Intelligence, Herndon, VA, 2013, pp. 159-166.

MEC (1997) "Diplomação, retenção e evasão nos cursos de graduação em instituições de ensino superior públicas”, Ministério da Educação, Comissão Especial de Estudos sobre a Evasão nas Universidades Públicas Brasileiras, ANDIFES/ABRUEM/SESu/MEC, Secretaria de Educação Superior, Brasília.

Queiroga, E. M., Cechinel, C., Araujo, R. M. (2015) “Um Estudo do Uso de Contagem de Interações Semanais para Predição Precoce de Evasão em Educação a Distância”, CBIE-LACLO 2015, pág. 1074-1083.

Reino, L. R. A. C., Domínguez, A. H., Junior, O. G. F., Carvalho, V. D. H., Barros, P. A. M., Braga, M. M. (2015) “Análise das Causas da Evasão na Educação a Distância em uma Instituição Federal de Ensino Superior”, SBIE 2015, pág. 91.

Rigo, S. R., Cambruzzi, W., Barbosa, J. L. V., Cazella, S. C. (2014) “Aplicações de Mineração de Dados Educacionais e Learning Analytics com foco na evasão escolar: oportunidades e desafios”, REVISTA BRASILEIRA DE INFORMÁTICA NA EDUCAÇÃO, v. 22, n. 01 (2014), DOI: 10.5753/RBIE.2014.22.01.132

Silva, F. C., Fonseca, L. C. C., Silva, J. C., Silva, R. J. S. (2015) “Uma ferramenta para visualização das tendências de evasão geradas por mineração de dados a partir das interações em fóruns de discussão”, LACLO 2015, pág. 237. 